\title{
A Montanha-Russa do Financiamento de Campanhas Eleitorais no Brasil: algumas considerações sobre o Relatório Parcial no 3 da Comissão Especial para Análise, Estudo e Formulação de Proposições Relacionadas à Reforma Política (CEPOLITI)
}

\author{
The Roller Coaster of Financing of Electoral Campaigns in Brazil: some \\ considerations about the 3o $r$ progress report of the special Commission for Analysis, \\ Studies and Formulation of Propositions Related to Political Reform (CEPOLITI)
}

Ana Claudia Santano

Resumo: A Comissão Especial para Análise, Estudo e Formulação de Proposições Relacionadas à Reforma Política já vem atuando a alguns meses, elaborando uma proposta de modificação da legislação eleitoral que, caso aprovada, irá alterar em profundidade todo o sistema vigente. É partindo destas sugestões que o trabalho aborda a questão do financiamento de campanhas eleitorais, considerando o modelo que está sendo aplicado e comparando-o com as mudanças sugeridas pela Comissão. Expõem-se as linhas gerais de cada uma das medidas trazidas no relatório parcial $\mathrm{n}^{\circ} 3$, trazendo também algumas consequências que podem vir com esse forte giro para o modelo público de financiamento. Ao final, são citadas algumas conclusões desta análise.

Palavras-chave: Financiamento; Campanhas Eleitorais; Partidos Políticos; Reforma Política; Democracia.

\begin{abstract}
The Special Commission for analysis, studies and formulation of propositions related to political reform is working for some months, elaborating one huge modification in the electoral legislation currently in force. In case of approval of these proposals, it will change deeply the current system applied. Going from this point, this paper aims to expose what are these new proposals, comparing them to the measures now applied. It is exposed also the general view of the 3rd progress report suggested by the Commission, bringing some lights on what the consequences of these project, after its approval. In the end, are being underlined some conclusions of this analysis.
\end{abstract}

Keywords: Financing; Electoral Campaigns; Political Parties; Political Reform; Democracy.

Artigo recebido em 23 jun. 2017 e aprovado em 27 set. 2017. 


\section{Reforma Política... de novo?}

Contra fatos, não há argumentos. O Brasil possui, como se uma tradição fosse, uma reforma política intermitente, com efeitos temporários e eventualmente dispositivos com perfil transitório. Há pelo menos duas décadas foi aprovada uma lei alterando a legislação eleitoral em ano ímpar, ${ }^{1}$ fato esse que é possível constatar ao observar a movimentação do Congresso Nacional sempre passado o período eleitoral propriamente dito, realizados em ano par.

Isso se repete em 2017. Nem bem a Lei no $13.165 / 2015$, responsável pela última reforma em profundidade, foi aplicada às eleições municipais de 2016, já se desenha uma mudança ainda maior de todo o arcabouço jurídico eleitoral, alcançando as Leis $\mathrm{n}^{\circ}$ 9.096/95, nำ 9.504/97, nº 4.767/65 (Código Eleitoral), bem como a no 13.165/15. Para essa tarefa, foi instituída a Comissão Especial para Análise, Estudo e Formulação de Proposições Relacionadas à Reforma Política (CEPOLITI), composta por 34 Deputados Federais.

O objetivo deste trabalho é analisar as propostas sobre financiamento de campanhas eleitorais constantes no Relatório Parcial n 3, da CEPOLITI, documento esse oriundo de processo de debate das sugestões trazidas, e produzido em meio a uma grave crise política que assola tanto a Presidência da República como uma parte expressiva de Deputados e Senadores ${ }^{2}$. Ou seja, o contexto de abalo dos Poderes Legislativo e Executivo, devido aos frequentes e muito preocupantes casos de corrupção, é um fator a se considerar nessa reforma que, ao contrário das anteriores, visa, ainda que indiretamente, a sobrevivência das forças políticas em um momento de notório descrédito na política pela população brasileira ${ }^{3}$.

\footnotetext{
${ }^{1}$ Isso já ocorreu em ano par. No entanto, isso vem de encontro com o disposto no art. 16, da Constituição Federal, que estabelece o princípio da anualidade, podendo afetar as disposições aprovadas, como ocorreu com a Lei no 11.300/2006, chamada, como tantas outras, de "minirreforma" eleitoral. Eis o teor do art. 16 da Constituição: "A lei que alterar o processo eleitoral entrará em vigor na data de sua publicação, não se aplicando à eleição que ocorra até um ano da data de sua vigência."

${ }^{2}$ Refere-se aqui às investigações conhecidas como "Lava jato", que revelam, durante a sua atuação, um esquema de corrupção que alcança muitos Deputados Federais e Senadores, havendo suspeitas também sobre o Presidente da República e seus antecessores.

${ }^{3}$ Muitas reformas no mundo todo são fruto de momentos de pouca reflexão, sendo, muitas vezes, somente uma reação para a revelação de escândalos de corrupção, sem a devida análise sobre possíveis consequências. Isso possibilita a criação de outros problemas além dos
} 
Os eixos principais das propostas unem dois objetivos da CEPOLITI. Um deles, o de alterar o sistema eleitoral a partir da adoção do sistema eleitoral distrital misto, tendo como sistema sugerido de modo transitório o de listas preordenadas, a ser aplicado, caso aprovado, tão somente às eleições de 2018 e 2020. O outro objetivo é tornar o sistema de financiamento de campanhas inteiramente público, através da criação de um Fundo Especial para o Financiamento da Democracia (FFD), o que torna ambas as medidas uma o encaixe da outra. É essa a razão principal delas virem juntas nessa reforma que se pretende, dando azo a uma profunda modificação no modelo aplicado até hoje ${ }^{4}$.

Vale ressaltar que o surgimento da pressão pela presença marcante do financiamento público para as campanhas eleitorais vem na esteira da escassez de recursos já verificada nas eleições de 2016, primeira realizada sob a proibição de doações de pessoas jurídicas para esse fim ${ }^{5}$, além do baixo nível de participação por meio de aportes de pessoas físicas ${ }^{6}$.

já existentes antes das reformas. Sobre o tema, MILYO (1999), PINTO-DUSCHINSKY (2002) e SANTANO (2016).

${ }^{4}$ Há muitas outras sugestões de alteração de regras, como no que se refere a registro de candidatos; federação de partidos; proibição de coligações para eleições proporcionais; estabelecimento da competência da Justiça Eleitoral para julgar disputas intrapartidárias; etc. No entanto, é clara a concentração dos esforços em torno ao financiamento de campanhas e ao sistema eleitoral.

${ }^{5}$ Vide ADI 4.650, STF. Rel. Min. Luiz Fux. Isso se extrai, inclusive, da justificativa dada pelo relator da CEPOLITI, Dep. Fed. Vicente Cândido (PT/SP), ao rejeitar a sugestão no 12 ao PL do Relatório, dos Deputados Chico Alencar e Luiza Erundina (PSOL), que propunha a supressão do art. 17-B, da Lei no 9.504/97, o qual institui o FFD: "Com a proibição do financiamento empresarial de campanhas eleitorais, o financiamento público se apresenta como a alternativa mais viável e consentânea com o interesse público e a criação de um Fundo Público com regras específicas que garantam uma distribuição equilibrada dos recursos públicos entre os partidos e as diversas campanhas eleitorais legislativas e executivas, majoritárias e proporcionais, mostra-se, ao nosso ver, como a solução mais adequada para o atual momento da política nacional." (Vide relatório parcial n. 3/17 da CEPOLITI, disponível em: < http://www2.camara.leg.br/atividade-legislativa/comissoes/comissoes-temporarias/especiais/55a-legislatura/reforma-politica/proposicao/pareceres-e-relatorios>. Acesso em: 23 jun. 2017.

${ }^{6}$ Essa pressão, de fato, surgiu já na apresentação do Projeto de Lei nº 6368/2016, Câmara dos Deputados, de autoria do Dep. Marcus Pestana (PSDB-MG). Esse PL visa a adoção de um sistema exclusivamente público de financiamento de campanhas eleitorais e de partidos políticos, a partir da criação de um Fundo Especial para o Financiamento da Democracia (daqui a ideia de criação desse fundo), composto por recursos oriundos da arrecadação do imposto de renda de pessoa física, com critérios de acesso a partir da representação Resenha Eleitoral (Florianópolis), v. 21, n. 1, p. 9-28, nov. 2017 
Assim, expor-se-ão as sugestões segundo o diploma legal alterado, na ordem constante no relatório, a fim de sistematizar bem as informações sobre o objeto em questão.

\section{Modificações na Lei no $^{\mathbf{9}} \mathbf{9 0 9 6} / 95$}

No que se refere à Lei de Partidos, não há muitas alterações, embora as existentes já possam causar, caso sejam aprovadas, impacto sobre a legislação vigente. As sugestões alcançam o rol de fontes vedadas e a destinação de recursos do Fundo Partidário.

No que se refere à lista de impedidos de realizar doações, foram incluídas no art. 31 as pessoas jurídicas, harmonizando o texto legal com a decisão do Supremo Tribunal Federal sobre o tema, acrescentando, ainda, os entes públicos de qualquer natureza, bem como pessoas físicas que exerçam função ou cargo público de livre nomeação e exoneração, cargo ou emprego público temporário, ressalvados os filiados a partidos políticos, estando estes autorizados a realizar aportes de até 10\% (dez por cento) dos rendimentos brutos relacionados com o exercício de suas atividades públicas auferidos no ano anterior ao da doação.

Por outro lado, no que tange à destinação dos recursos do Fundo Partidário, há a inserção do inciso V-A, que direciona o mínimo de $2 \%$ (dois por cento) do total endereçado às fundações e institutos partidários para a criação e a manutenção de programas de fomento à participação de jovens na atividade política. Caberá à direção do Órgão Nacional determinar o montante a ser utilizado para esse fim. Caso se descumpra essa regra, o partido deverá, no exercício seguinte, aplicar 2,5 vezes o percentual anteriormente devido, segundo o novo $\$ 5^{\circ}$-A. Por outro lado, caso o instituto ou a fundação não despenda todos os valores, poderá reverter o saldo para outras atividades do partido, conforme o texto do $\$ 6^{\circ}$.

Há também alterações no $\int 5^{\circ}$, o qual antes previa o acréscimo de $12,5 \%$ (doze e meio por cento) do valor destinado à promoção da participação política das mulheres, sendo agora esse percentual calculado sobre o total do montante do Fundo Partidário recebido pelo partido. Há, nesse

partidária no Congresso Nacional, e de distribuição dos recursos que se assemelham aos utilizados para o vigente Fundo Partidário. Para um estudo completo sobre este PL, vide SANTANO (2017). 
sentido, uma reafirmação das ações que fomentam a participação das mulheres na política dentro do sistema do Fundo Partidário, que se destina ao financiamento ordinário dos partidos. Vale destacar aqui que há diversas medidas que visam esse fim, o que se celebra, considerando o desempenho muito criticável das cotas de gênero na apresentação de candidaturas ${ }^{7}$.

\section{Modificações na Lei no 9.504/97}

Indubitavelmente, as principais alterações trazidas pelo Relatório incidem sobre a Lei das Eleições, estando por todo o texto da norma em vigor. A fim de sistematizar melhor o volume das sugestões, separar-se-á por temas relacionados com o financiamento de campanhas, ressaltando que há muitas outras modificações que aqui não serão abordadas.

\subsection{A Instituição das Primárias Partidárias}

Uma das novidades que o Relatório traz é a adoção do sistema de primárias para a seleção de candidatos, uma vez que o mesmo documento aporta o modelo de votação em listas preordenadas para se seguir ao distrital misto após duas eleições (2018 e 2020).

Assim, foram acrescentados os arts. 8-A, B e C, com parágrafos e incisos, estabelecendo um teto para os gastos do partido na realização de primárias no valor de $\mathrm{R} \$ 18.000 .000,00$ (dezoito milhões de reais), para o custeio da propaganda intrapartidária e da organização das votações, bem como a possibilidade de se realizar doações como pessoa física, limitadas até dois salários mínimos, tendo como destinatário final um pré-candidato indicado pelo doador. Estes aportes serão feitos para a conta de recursos próprios do partido e, logo, encaminhados ao pré-candidato previamente nomeado. Junto a isso, resta vedado o autofinanciamento de pré-candidatos.

Ainda que se possa olhar com bons olhos a adoção de primárias, as regras referentes ao financiamento desse processo são lacunosas em aspectos importantes. Não há disposições sobre a prestação de contas desses valores, sobre eventual controle de gastos pelos pré-candidatos, bem como outros detalhes que se fazem, aqui, muito relevantes. Pode-se supor que tudo será feito na ocasião da prestação de contas dos partidos, já que a conta utilizada será a de "recursos próprios", mas essa condição deveria estar clara, não ser fruto de suposição.

${ }^{7}$ Sobre o tema, FREITAS apud PEREIRA, 2016, p. 119-138.

Resenha Eleitoral (Florianópolis), v. 21, n. 1, p. 9-28, nov. 2017 
Do mesmo modo, não constam disposições sobre a efetiva entrega dos recursos doados ao pré-candidato determinado pelo doador, nem em medidas a se recorrer, caso isso não seja providenciado pela agremiação. As disputas intrapartidárias podem ser acirradas, o que faz com que essa lacuna possibilite a violação de direitos dos pré-candidatos não alinhados com a elite partidária. Vale lembrar que não há nenhuma remissão ao tema das primárias e seu financiamento na Lei no 9.096/95, gerando ainda mais insegurança no momento de aplicação das regras.

\subsection{O Financiamento Público de Campanhas - o fundo espe- cial de financiamento da democracia}

Um ponto central da proposta da CEPOLITI se traduz em uma mudança muito expressiva das medidas vigentes de financiamento público de campanhas, estabelecendo o sistema público exclusivo para eleições proporcionais (art. 17, parágrafo único), e um misto - muito tendente ao público -, para os pleitos majoritários (art. 20).

Os recursos públicos serão destinados às campanhas por meio da criação do Fundo Especial de Financiamento da Democracia (FFD art. 17-B), com a finalidade de prover recursos financeiros para o custeio das atividades eleitorais e da realização dos plebiscitos e referendos, aquele constituído por recursos do orçamento da União. As dotações do Fundo, identificada a correspondente fonte de custeio, serão incluídas na lei orçamentária correspondente ao ano eleitoral ou, quando houver plebiscito ou referendo, em rubricas próprias e alocadas em unidade orçamentária no âmbito do Poder Executivo. Logo, caberá ao Tribunal Superior Eleitoral a fiscalização da distribuição e da utilização dos valores destinados a cada partido ou frente suprapartidária.

Esse Fundo Especial de Financiamento da Democracia já constava no PL nº 6368/2016, já citado neste trabalho. A diferença de ambos os modelos é a sua configuração, que naquele PL já se julgava inadequada. Nesse sentido, o FFD trazido pelo Projeto de Lei nº 6388/2016 tinha os seguintes percentuais para a sua aplicação:

- 7\% para Presidente da República;

- 3\% para Senador da República;

- 10\% para Deputado Federal;

- 10\% para Deputado Estadual; 
- $15 \%$ para Governador;

- 25\% para Prefeito;

- 15\% para Vereador;

- 15\% dos recursos para custeio das atividades partidárias e seu funcionamento regular (aqui, o Fundo substituía o Fundo Partidário por completo).

Já os critérios daquele modelo eram semelhantes para o acesso e o reparto dos recursos públicos já existentes para o Fundo Partidário:

- 5\% (cinco por cento) a todos os partidos, em partes iguais, com representação no Congresso Nacional;

- $95 \%$ (noventa e cinco por cento) serão distribuídos aos partidos na proporção dos votos obtidos na última eleição geral para a Câmara dos Deputados.

No PL proposto pelo Relatório ora analisado, o FFD é muito mais detalhado e mais restrito em seu acesso e distribuição. Pior: as disposições que tratam sobre a composição do FFD e suas vicissitudes foram elaboradas exclusivamente para as eleições gerais de 2018, o que deixa evidenciado o seu caráter transitório (já exigindo eventual modificação em um curto prazo de tempo).

Ainda, essas medidas não serão inseridas nas normas eleitorais já existentes, em caso de aprovação do PL constante no Relatório Parcial, nem mesmo na Lei n⿳9 9.504/97, fazendo com que a norma que se aprove seja mais uma a formar o arcabouço legislativo eleitoral do Brasil, colaborando ainda mais com a fragmentação legislativa sobre a matéria.

Para a aplicação dos recursos do FFD - que se faz sem extinguir o Fundo Partidário -, é destinado o valor total de R $\$ 1.900 .000 .000,00$ (um bilhão e novecentos milhões de reais) para as campanhas das eleições de 2018 para Senador da República, listas preordenadas para Deputado Federal, Estadual e Distrital, bem como para o $1^{\circ}$ turno para o Governo dos Estados e a Presidência da República.

Ainda há R \$285.000.000,00 (duzentos e oitenta e cinco milhões de reais) destinados para o $2^{\circ}$ turno para o Governo dos Estados e a Presidência da República (art. 7ํㅡㄹ do PL proposto pelo Relatório) ${ }^{8}$.

\footnotetext{
${ }^{8} \mathrm{O}$ responsável pelo cálculo correspondente a cada partido que tenha direito a esses recursos será o Tribunal Superior Eleitoral.
} 
A distribuição desses valores (art. $8^{\circ}$ ) será feita em duas etapas: (i) definição do valor global correspondente a todas as campanhas; (ii) definição de valores para cada partido. Considerando o valor total para todas as campanhas, haverá a divisão de 70\% (setenta por cento) para cargos no Poder Executivo, sendo 40\% (quarenta por cento) para o cargo de presidente e 60\% (sessenta por cento) para governador; e os restantes 30\% (trinta por cento) para cargos no Poder Legislativo, ou seja, as listas preordenadas.

No que tange à distribuição dos recursos entre os partidos, serão: (i) $2 \%$ (dois por cento) em partes iguais entre todos os partidos com estatutos registrados no Tribunal Superior Eleitoral; (ii) 98\% (noventa e oito por cento), divididos entre os partidos, na proporção do percentual de votos obtido na última eleição geral para a Câmara dos Deputados.

Nesse ponto, o problema não está na divisão de recursos entre as campanhas, mas na desigual proporção adotada nos critérios de acesso e reparto dos montantes entre as forças políticas. Destinar somente $2 \%$ a todos os partidos registrados no TSE é restringir em demasia o acesso a esses recursos, sem fundamento constitucional para isso. Há uma inegável desproporção entre os $2 \%$ e os $98 \%$, o que provoca ainda mais desigualdade entre as oportunidades das organizações partidárias, premiando também de forma desproporcional os partidos majoritários.

Com isso, organizações partidárias majoritárias sempre serão beneficiárias de recursos públicos, petrificando o status quo. Os partidos majoritários já contam com a visibilidade de sua presença no Estado e já possuem uma forte estrutura partidária. Colocá-los em uma posição hegemônica não parece uma alternativa adequada diante do princípio da igualdade e do princípio democrático, muito menos se isso for uma resposta à grave crise política que se presencia, como aparenta ser ${ }^{9}$.

Cabe acrescentar que o requisito dos "votos obtidos na última eleição geral para a Câmara dos Deputados” produz dois efeitos que se julgam negativos: exclui as novas agremiações (que não participaram ainda de nenhuma eleição geral), e favorece injustificadamente os candidatos eleitos na Câmara, em detrimento dos votos dos eleitos no Senado, sendo que eleger um senador é muito mais difícil do que um deputado federal ${ }^{10}$.

\footnotetext{
${ }^{9}$ A mesma crítica foi feita ao PL nº 6368/2016. No entanto, no Relatório da CEPOLITI nota-se o agravamento da desproporcionalidade já indicada.

${ }^{10}$ A mesma crítica foi feita ao PL n⿳o 6368/2016.
} 


\subsection{Do Plano de Aplicação de Recursos (PAR)}

Para que tais recursos sejam recebidos pelos partidos, é necessário que a agremiação previamente aprove o Plano de Aplicação de Recursos (PAR), pela maioria absoluta de seus membros (parágrafo único do art. $7^{\circ}$ do PL proposto pelo Relatório). Essa medida já constava no PL n⿳ 6368/2016, da mesma forma lacunosa. Naquele projeto de lei, fazia-se uma mera menção ao PAR no art. 43, §3º, a ser inserido na Lei nº 9.096/95, exigindo também a sua aprovação pela maioria absoluta dos membros da agremiação, sem outros detalhes importantes, como a eventual não aprovação do PAR.

Permanece aqui a dúvida sobre o que ocorre com os recursos públicos na ausência do PAR, bem como se é possível que esse quórum qualificado possa ser estabelecido por lei externa e não pelo estatuto dos partidos.

Além disso, da mesma maneira que o projeto de lei anterior, esse silencia sobre o conteúdo do PAR, sendo ainda mais vago do que o PL no 6368/2016, já que este ao menos fixava, em seu art. 2º parágrafo único, que os partidos deverão considerar, ao realizarem a aplicação dos recursos, os ideais, princípios e valores partidários, o peso populacional das unidades da federação, políticas de redução de desigualdade, bem como a democratização de oportunidades.

A única menção ao PAR no PL constante no Relatório da CEPOLITI é que ele deve ser aprovado pela maioria absoluta dos membros do partido, sob pena do não recebimento dos recursos públicos para o financiamento das campanhas.

\subsection{Da Distribuição dos Recursos do FFD aos Partidos a partir dos Cargos Disputados}

Como os valores a serem destinados às organizações partidárias serão globais, o PL apresentado pelo Relatório traz a forma de divisão desse montante entre as diversas campanhas a se realizar. Aqui se verifica a necessidade de aperfeiçoamento da redação dos dispositivos para uma melhor técnica legislativa. 
Para o cargo de Presidente da República, a divisão será:

- o partido que solicitar o registro da candidatura receberá a integralidade de sua cota;

- o partido integrante de uma coligação, sem que os candidatos ao cargo de titular ou de vice sejam a ele filiados, receberá a integralidade de sua cota, devendo destinar pelo menos 60\% (sessenta por cento) para o candidato da coligação, podendo redistribuir até $40 \%$ (quarenta por cento) dos recursos recebidos, entre suas candidaturas próprias a governador;

- o partido que não solicitar registro de candidato e não fizer parte de coligação receberá $60 \%$ (sessenta por cento) de sua cota para redistribuição entre suas candidaturas a governador, e os demais $40 \%$ (quarenta por cento) retornarão ao Tesouro Nacional.

Já para o cargo de Governador de Estado, a divisão atenderá à seguinte fórmula:

- o partido que solicitar registro de candidato receberá a integralidade de sua cota;

- o partido que fizer parte de pelo menos uma coligação, sem ter nenhum candidato próprio, receberá $60 \%$ (sessenta por cento) de sua cota para destinar aos candidatos da coligação e os demais 40\% (quarenta por cento) retornarão ao Tesouro Nacional;

- o partido que não solicitar registro de candidato e não fizer parte de coligação não receberá sua cota.

Por último, para as campanhas de segundo turno, a divisão dos recursos públicos será:

- para campanha de Presidente 35\% (trinta e cinco por cento) do total;

- para campanha de Governadores 65\% (sessenta e cinco por cento) do total, distribuídos entre as circunscrições nas quais houver segundo turno, na proporção dos limites de gastos para o primeiro turno (art. 15, $\int 1^{\circ}$, a seguir abordado).

Nenhuma campanha de Presidente ou de Governador poderá receber mais de $70 \%$ (setenta por cento) do limite estabelecido para gastos com segundo turno na respectiva circunscrição. 
Ainda, os recursos destinados às campanhas eleitorais no segundo turno serão distribuídos igualitariamente entre os concorrentes. Em caso de não haver eleição de segundo turno para Presidente, o montante reservado retornará ao Tesouro Nacional,

Trata-se de uma fórmula complexa de divisão dos recursos públicos, com o objetivo de ser o mais equânime possível entre todas as candidaturas.

Uma indagação que se pode extrair desse ponto é a percepção de que há, indiretamente, certo fomento à apresentação de candidaturas próprias, uma vez que partidos que apresentem seus próprios candidatos recebem a cota integral a que têm direito. Visto sob esse ponto de vista, a medida é benéfica e favorece o cumprimento de uma das principais funções dos partidos: a de selecionar candidatos e lançá-los. Isso os fortalece, contribui para maior "oferta" de opções políticas, e amplia a variedade ideológica que pode haver em uma campanha ${ }^{11}$.

Por outro lado, aparenta também que está se criando uma espécie de "categorias" de partido, como principais (os que apresentam candidaturas) e os acessórios (que se coligam para as eleições majoritárias). Se isso não passar de mera impressão, não parece haver problemas na fórmula adotada.

\subsection{O Regime de Doações Privadas}

Voltando às alterações da Lei nº 9.504/97, há algumas alterações referentes às fontes permitidas de financiamento, bem como a administração financeira da campanha e doações privadas de pessoas físicas.

$\mathrm{O}$ art. 20 dispõe que o candidato (nesse caso, subentende-se que é o majoritário, tendo em vista que o PL do Relatório não especifica) ou pessoa por ele designada fará a administração financeira de sua campanha, usando as seguintes fontes de financiamento: (i) recursos do FFD; (ii) cota do Fundo Partidário; (iii) recursos próprios; (iv) doações de pessoas físicas. Além disso, a obrigatoriedade da abertura de uma conta bancária específica também é estabelecida para cada lista preordenada de candidatos para as eleições proporcionais, cabendo ao partido essa providência.

O limite de doação para as pessoas físicas sofre alterações segundo o PL ora em comento (art. 23, $\$ 1^{\circ}$ ). Somadas todas as realizadas pelo mesmo doador, será o menor valor entre os $10 \%$ dos rendimentos brutos auferidos no ano anterior às eleições e 10 (dez) salários mínimos.

${ }^{11}$ Nesse sentido, SANTANO, 2016. 
Outro limite que foi reduzido foi o da utilização de recursos próprios, o qual também atende à formula acima mencionada. Tais modificações deixam clara a intenção da CEPOLITI na inclinação para o modelo público de financiamento de campanhas.

Outra novidade vem na alteração do $\int 4^{\circ}$ do art. 23 da Lei $n^{\circ}$ 9.504/97, modificado por esse PL, introduzindo ferramentas de financiamento coletivo de campanhas:

- por meio de plataforma eletrônica disponibilizada pelo Tribunal Superior Eleitoral para esse fim;

- por meio de aplicativos eletrônicos, sítios da internet e técnicas e serviços de financiamento coletivo, desde que: (i) exista o seu cadastro prévio na Justiça Eleitoral, que estabelecerá regulamentação para a prestação de contas e fiscalização instantânea das doações e repasses ao candidato; (ii) identificação obrigatória de cada um dos doadores e das respectivas quantias doadas; (iii) disponibilização da lista de doadores e valores doados, com atualização simultânea; (iv) emissão obrigatória de recibo eleitoral para o doador, sob responsabilidade da entidade arrecadadora, com envio imediato das informações à Justiça Eleitoral e ao candidato; (v) ampla ciência aos candidatos e eleitores sobre as taxas administrativas cobradas pelo serviço de arrecadação de doações; (vi) os recursos não podem incidir em nenhuma das fontes vedadas constante no art. 24 da Lei 9.504/97; (vii) observância do calendário eleitoral, notadamente do período de arrecadação de recursos; (viii) obediência às regras de propaganda na internet.

Essas medidas alinham a proposta aos instrumentos mais modernos de arrecadação de recursos de campanha, demonstrando que não há como escapar dos avanços tecnológicos que já estão sendo amplamente usados para tal fim em outros países ${ }^{12}$. Contudo, os seus benefícios serão bastante reduzidos se o formato constante no PL do Relatório realmente for aprovado, uma vez que somente as campanhas majoritárias poderão desfrutar dessa alternativa, desconsiderando todas as vantagens dessas ferramentas no financiamento de campanhas proporcionais, as quais têm o seu custeio pago integralmente com recursos públicos oriundos do FFD.

${ }^{12}$ Sobre o tema, SANTANO, 2016, p. 29-68. 
Importante alertar que essa pode ser a conclusão decorrente de mera dedução, a partir do art. 17, parágrafo único, da Lei no 9.504/97, alterado pelo PL do Relatório ora comentado. O dispositivo diz que os gastos de campanha com as listas preordenadas de candidatos para as eleições proporcionais serão de responsabilidade exclusiva dos partidos, excetuando os de natureza pessoal dos candidatos. Se o sistema de votação deixará de ser nominal, devendo os eleitores votar em uma lista definida e bloqueada pelos partidos proponentes, a priori não há outra opção senão deduzir que não haverá possibilidade de doação para a pessoa do candidato, ainda mais porque o PL nada diz a respeito. Assim, o financiamento coletivo - a partir dessa conclusão - alcançará somente as candidaturas majoritárias, o que limita seus benefícios ao sistema como um todo.

Ainda sobre limites de doações, também é objeto de redução o teto das doações estimáveis, o qual havia passado de $\mathrm{R} \$ 50.000,00$ (cinquenta mil reais) para $\mathrm{R} \$ 80.000,00$ (oitenta mil reais), mas agora é de $\mathrm{R} \$$ 40.000,00 (quarenta mil reais), restringindo mais a participação nas campanhas por meio de aportes privados.

Por outro lado, no que se refere às providências que se viram necessárias às eleições de 2016, foi a regulação - ainda que breve -, sobre a utilização de cartões de crédito para a realização de doações privadas pela internet, com a vedação de recusa, por parte das instituições financeiras, da utilização dos cartões de crédito para esses fins.

Isso provavelmente diminui os transtornos causados por essas instituições durante a campanha realizada, sendo uma medida bem-vinda para uma maior exploração das fontes permitidas de arrecadação. No entanto, junto com isso há o estabelecimento da responsabilidade pela verificação da origem e da licitude dos recursos transferidos por meio de cartão de crédito para o candidato e, caso designado, o administrador financeiro, presidentes e tesoureiros de partidos políticos, algo que se julga bastante polêmico e de difícil aplicação.

Conhece-se o problema da infiltração de recursos ilícitos nas campanhas, mas o ônus dessa fiscalização e do saneamento do sistema não deveria passar pelos agentes listados. Durante uma campanha, com o movimento intenso de recursos, entende-se ser muito difícil, senão impossível, realizar a contento essa obrigação, o que poderá gerar transtornos caso a medida seja aprovada. 


\subsection{Limite de Gastos}

Outro tema que não é inserido nas alterações de leis já existentes, mas que virá a compor o arcabouço jurídico eleitoral através da eventual aprovação do PL, constante no Relatório que ora se comenta, é referente ao limite de gastos nas campanhas. Aqui também há a clara transitoriedade da fórmula, tendo em vista que as regras dispostas nos arts. 14, e seguintes, do PL se restringem às eleições de 2018, pairando dúvidas sobre sua continuidade.

Para o cargo de Presidente da República, o limite de gastos será de $\mathrm{R} \$$ 150.000.000,00 (cento e cinquenta milhões de reais). Caso haja $2^{\circ}$ turno, o valor será 50\% (cinquenta por cento) do indicado (art. 14).

Já o art. 15 traz uma fórmula de cálculo do limite de gastos para as campanhas para Governador, Senador e Deputado Federal, Estadual e Distrital, com base no número de eleitores por Unidade da Federação.

Nas eleições para Governador, considerando a população nas Unidades da Federação:

- com até um milhão de eleitores, $\mathrm{R} \$ 4.000 .000$ (quatro milhões de reais);

- com mais de um milhão de eleitores e até dois milhões de eleitores, $\mathrm{R} \$ 7.000 .000,00$ (sete milhões de reais);

- com mais de dois milhões de eleitores e até quatro milhões de eleitores, $\mathrm{R} \$$ 8.000.000,00 (oito milhões de reais);

- com mais de quatro milhões de eleitores e até oito milhões de eleitores, $\mathrm{R} \$$ 13.000.000,00 (treze milhões de reais);

- com mais de oito milhões de eleitores e até vinte milhões de eleitores, $\mathrm{R} \$ 16.000 .000,00$ (dezesseis milhões de reais);

- com mais de vinte milhões de eleitores, $\mathrm{R} \$ 30.000 .000,00$ (trinta milhões de reais).

Já para as eleições para Senador, os limites referentes à população em cada Unidade da Federação são:

- com até um milhão de eleitores, $\mathrm{R} \$ 1.500 .000$ (um milhão e quinhentos mil reais);

- com mais de um milhão de eleitores e até dois milhões de eleitores, $\mathrm{R} \$ 2.000 .000,00$ (dois milhões de reais); 
- com mais de dois milhões de eleitores e até quatro milhões de eleitores, $\mathrm{R} \$ 2.500 .000$ (dois milhões e quinhentos mil reais);

- com mais de quatro milhões de eleitores e até oito milhões de eleitores, R \$3.500.000,00 (três milhões e quinhentos mil reais);

- com mais de oito milhões de eleitores e até vinte milhões de eleitores, $\mathrm{R} \$ 5.000 .000,00$ (cinco milhões de reais);

- com mais de vinte milhões de eleitores $\mathrm{R} \$$ 8.000.000,00 (oito milhões de reais).

Nas eleições para Deputado Federal, Distrital e Estadual, os limites populacionais nas Unidades da Federação para cada lista de candidatos são:

- com até um milhão de eleitores, $\mathrm{R} \$ 2.000 .000$ (dois milhões de reais);

- com mais de um milhão de eleitores e até dois milhões de eleitores, $\mathrm{R} \$ 3.500 .000,00$ (três milhões e quinhentos mil reais);

- com mais de dois milhões de eleitores e até quatro milhões de eleitores, $\mathrm{R} \$ 4.000 .000,00$ (quatro milhões de reais);

- com mais de quatro milhões de eleitores e até oito milhões de eleitores, R\$ 6.500.000,00 (seis milhões e quinhentos mil reais);

- com mais de oito milhões de eleitores e até vinte milhões de eleitores, $\mathrm{R} \$$ 8.000.000,00 (oito milhões de reais);

- com mais de vinte milhões de eleitores, $\mathrm{R} \$ 15.000 .000,00$ (quinze milhões de reais).

Em comparação com a fórmula de cálculo do limite de gastos trazida com a aprovação da Lei no $13.165 / 2015$, há muito mais vantagem nessa, sendo também a sistemática de outros países, como a Espanha. No entanto, não há explicação que se possa deduzir sobre a progressão aritmética dos valores, o que prejudica a opção aportada pelo PL do Relatório. Ou seja: no caso do cargo de Governador, pode-se gastar até quatro milhões de reais em Estados de até um milhão de eleitores, de um a dois milhões de eleitores, pode-se gastar quase a metade, e de dois a quatro milhões de eleitores, pode-se gastar oito milhões de reais? Não há lógica no estabelecimento desses valores, podendo (se bem analisado) gerar desigualdades entre os Estados da Federação, aumentando os conflitos internos já existentes e muito afetados pelo sistema eleitoral vigente. 
Outra novidade que traz o PL é que os recursos públicos destinados às campanhas somente podem custear até $70 \%$ (setenta por cento) do limite de gastos à ela referente (art. 16, do PL do Relatório). Se ultrapassam esse percentual, os recursos excedentes podem ser destinados pelo partido ou federação de partidos para outras candidaturas, bem como podem retornar ao Tesouro Nacional. Isso se soma à disposição que estabelece que os recursos do FFD que não forem utilizados também regressem ao Tesouro Nacional.

Para finalizar as alterações no sistema de financiamento de campanhas sugeridas pelo PL, há o art. 17, o qual determina que, se doações de pessoas físicas a candidatos ou a listas - sendo essa a primeira remissão a doações privadas a listas, o que se entende que são doações para os partidos - excederem o limite de gastos para a respectiva campanha, a sobra poderá ser transferida para o partido ou a federação de partidos do candidato ou da lista. Volta-se ao problema da lacuna havida sobre doações privadas para listas preordenadas.

\subsection{Prestação de Contas}

Há alterações pontuais no procedimento de prestação de contas, não modificando substancialmente ao que já se aplica. Isso é muito criticável, uma vez que o tema da fiscalização e da verificação das contas é central no combate à corrupção e à lavagem de dinheiro por meio das campanhas eleitorais. Não se percebe movimentações a respeito desses tópicos a fim de fortalecer os mecanismos de controle, muito menos no reforço do sistema sancionatório, muito carecedor de efetividade, o que o faz uma letra normativa pouco dissuasória diante dos problemas do financiamento de campanhas ${ }^{13}$.

A prestação de contas das listas partidárias preordenadas para as eleições proporcionais será feita pelos partidos, sem qualquer outra menção sobre eventuais consequências no caso de não apresentação (art. 28, $₫ 2^{\circ}$, da Lei $n^{0}$ 9.504/97, alterado pelo PL trazido pelo Relatório). Essa lacuna abre a oportunidade para que os candidatos constantes na lista possam ser penalizados injustamente com a negação de sua quitação eleitoral caso o partido seja negligente e não cumpra o seu dever de apresentação das contas.

${ }^{13}$ Sobre o tema, GELAPE; VIDAL, 2017. 
Tal preocupação aumenta ainda mais com a leitura do art. 29, também modificado pelo Relatório, pelo qual se determina que os partidos encaminhem à Justiça Eleitoral o conjunto das prestações de contas das listas preordenadas e dos candidatos majoritários, consolidando as informações, mantendo-se o prazo de 30 dias após a realização das eleições, havendo somente a previsão de intimação do partido e pessoalmente do respectivo candidato cujas contas não tenham sido apresentadas para que as apresente no prazo de 48 (quarenta e oito) horas sob pena de serem consideradas como não prestadas, não havendo previsão de qualquer outra sanção e sem tratar sobre o caso das prestações de contas das listas (essa omissão deve ser sanada caso se aprove o PL, uma vez que é cediço que a única sanção referente à prestação de contas é a não quitação eleitoral para os casos de não apresentação).

Em não havendo a quitação eleitoral, os candidatos incluídos na lista tida como inadimplente diante da Justiça Eleitoral poderão ter seus direitos políticos afetados devido à inércia ou desídia do partido, o que, em definitiva, não se pode coadunar.

No que tange às outras modalidades de prestação de contas, mantêm-se a de 72 (setenta e duas) horas, alterando-se somente o início da contagem do prazo, sendo deslocado do recebimento para a ocorrência da doação ou do gasto, bem como a prestação de contas parcial, modificando-se a data de apresentação, que passa do dia 15 de setembro para o dia 31 de agosto.

Como medidas de desburocratização do procedimento, há: (i) a dispensa de comprovação na prestação de contas na cessão de automóvel próprio do candidato; do cônjuge e de parentes de até terceiro grau, quando destinado para o uso pessoal durante a campanha; (ii) tanto nas eleições majoritárias quanto as em lista, a dispensa de menção na prestação de contas do combustível e manutenção do automóvel próprio usado pelo candidato na campanha; da remuneração do motorista particular; da alimentação e hospedagem própria e do motorista; bem como o uso de linhas telefônicas registradas em nome de pessoa física próprio do candidato, até o limite de 3. Ainda que medidas tímidas, elas alcançam principalmente campanhas municipais de pequeno porte, o que se agradece, considerando a alta formalidade que sempre se fez muito presente diante de providências básicas dessas campanhas. 


\section{Modificações na Lei no ${ }^{-13.165 / 2015}$}

O único dispositivo alterado pela "minirreforma" anterior foi o art. 9o, que determina que, nas três eleições que se seguissem à sua aprovação, os partidos reservarão, em contas bancárias específicas para esse fim, no mínimo 5\% (cinco por cento) do montante do Fundo Partidário destinado ao financiamento das campanhas eleitorais para aplicação nas campanhas de suas candidatas, incluídos nesse valor os recursos a que se refere o inciso V do art. 44 da Lei no 9.096, de 19 de setembro de 1995.

Ocorre que na redação original desse dispositivo, há um máximo estabelecido de 15\% (quinze por cento), que foi objeto de contestação pelo Ministério Público Federal por meio da ADI 5617. O MPF alega que, se a cota de gênero para candidaturas é de, no mínimo, 30\% (trinta por cento) das listas, o mínimo a ser reservado pelos partidos também deve ser na mesma proporção, sob pena de violar o princípio da igualdade ${ }^{14}$. Parece que a inconstitucionalidade alegada permanece mesmo após o PL.

\section{Expectativas sobre o Projeto de Lei}

Ainda que o projeto de lei busque uma alternativa viável para o problema do financiamento de partidos e de campanhas eleitorais, não se recomenda medida tão drástica como a adoção de modelo que tende tanto ao público. Entende-se que outros canais poderiam ser mais adequados para o fomento não só da arrecadação de valores, mas que pudesse resgatar valores democráticos, como o incentivo à participação política popular por meio de pequenas doações. Isso poderia ser feito também através de imposto, porém, de deduções fiscais, algo que foi rejeitado pelo relator designado na CEPOLITI ${ }^{15}$. Não se concorda com essa rejeição à medida, porquanto comprovadamente é uma ferramenta que aumenta a arrecadação de doações de pequeno valor. Os que comprovassem doações até um determinado limite poderiam ter valores fiscais abatidos. É um mecanismo presente na Alemanha e que funciona há muitos anos.

\footnotetext{
${ }^{14}$ Decisão monocrática proferida no feito pelo Min. Relator, Edson Fachin, em 26 de outubro de 2016: "Tendo em vista a relevância da matéria debatida nos presentes autos e sua importância para a ordem social e segurança jurídica, adoto o rito positivado no artigo 12 da Lei n⿳o 9.868/1999, a fim de possibilitar ao Supremo Tribunal Federal a análise definitiva da questão.".

${ }^{15}$ Sugestão do Dep. Hildo Rocha (PMDB/MA), que foi rejeitada sob o argumento de que o FFD já faria o papel do financiamento público pretendido pelo PL.
} 
Aperfeiçoar as regras que permitam o uso de mecanismos do financiamento coletivo também é muito recomendável, encontrando uma forma de alcançar também os candidatos constantes nas listas preordenadas. Isso pode renovar os valores democráticos na sociedade e aumentar a participação popular nesse processo, trazendo legitimidade ao resultado e robustez à democracia.

Faltou preocupação também com maior transparência do financiamento. O mais indicado é tornar tudo o mais claro possível, é informar o eleitorado quem está financiando as campanhas e os partidos, e aperfeiçoar cada vez mais o sistema de fiscalização, sem o ânimo punitivo, mas sim dissuasório. Dessa forma, o eleitor é mais munido de informações para decidir o seu voto, transmitindo a ideia de que não vale tudo e que as leis devem ser cumpridas, garantindo, assim, o equilíbrio entre os candidatos mais e menos abastados. Combate-se a ideia de que só os mais abastados têm condições de serem eleitos.

Não se julga adequado fechar ainda mais o sistema político brasileiro. As regras limitativas e proibitivas abundam, estando em descompasso com os valores constitucionais de 1988, e com a atual situação da política brasileira, ainda mais destinando enorme quantia de recursos públicos diante de todas as carências do Estado brasileiro. Será uma tarefa muito difícil convencer os cidadãos de que isso é legítimo, quando o que há é um nítido contexto de demonização e criminalização da política.

\section{Referências}

FREITAS, Juliana Rodrigues. O sistema de cotas de gênero e o óbice ao desenvolvimento no Brasil: reflexões iniciais acerca da reduzida participação feminina na política brasileira. In: PEREIRA, Rodolfo Viana; SANTANO, Ana Claudia (Orgs.). Conexões Eleitoralistas. Belo Horizonte: Abradep, 2016. p. 119-138.

GELAPE, Lucas de Oliveira; VIDAL, Luísa Ferreira. Prestação de contas de campanhas eleitorais: (in) diferenças práticas entre a aprovação, aprovação com ressalvas, rejeição e não prestação de contas eleitorais. Disponível em: <http://www.publicadireito.com.br/artigos/?cod=b060700f0a542a14>. Acesso em: 23 jun. 2017.

MILYO, Jeffrey. The Political Economics of Campaign Finance. The Independent Review. v. III. $\mathrm{n}^{\circ}$ 4, [s.l.] 1999. p. 541-545. 
PINTO-DUSCHINSKY, Michael. Financing Politics: A Global View. Journal of Democracy. no 4, vol. 13, p. 69-86, oct.. John Hopkins University Press, Washington, 2002.

SANTANO, Ana Claudia. e-Leitor: Vamos discutir os deveres dos partidos na democracia brasileira?. JOTA, 01 mar. 2016. Disponível em: <https:// jota.info/colunas/e-leitor/e-leitor-vamos-discutir-os-deveres-dos-partidos-na-democracia-brasileira-01032016>. Acesso em: 29 maio 2017.

. La financiación de los partidos políticos en España. Madrid: CEPC, 2016.

. O financiamento coletivo de campanhas eleitorais como medida econômica de democratização das eleições. Estudos Eleitorais, v. 11, p. 29-68, 2016.

. Parecer jurídico - Projeto de Lei 6368/2016, Câmara dos Deputados. Revista eletrônica Direito e Política, v. 12, p. 462-481, 2017.

Ana Claudia Santano - Professora do programa de Mestrado em Direitos Fundamentais e Democracia, do Centro Universitário Autônomo do Brasil - Unibrasil. Pós-doutora em Direito Público Econômico pela Pontifícia Universidade Católica do Paraná. Doutora e Mestre em Ciências Jurídicas e Políticas pela Universidad de Salamanca, Espanha. Pesquisadora do Observatório de Financiamento Eleitoral, do Instituto Brasiliense de Direito Público, IDP. Currículo lattes: http:/ / lattes.cnpq.br/6241908411721255. 